\title{
Analysis of McDull Series and its Enlightenment to Chinese Animation
}

\author{
Films
}

\author{
Gengshuai \\ School of art and design, Wuhan University of Technology \\ 346591653@163.com
}

Keywords: Analysis, Enlightenment, Animation.

\begin{abstract}
With the first serialized in comic way in 1988, then the first animated film come out in 2001, and the third animated film released in the mainland film market in 2009. It took totally more than 20 years for"McDull" to complete its growth aprocess.
\end{abstract}

\section{Introduction}

In general, every step of its development for"McDull" , especially for "McDull" series animated films, has made a great achievement.

McDull animated films reflect the real social life of Hong Kong people. Concerning about their childhood, the old memories, the happiness and worries they have experienced, even the basic question between" existence" of human and" time" , inserts a deeper kernel into the story compared with other animated films.

However, such artistic techniques in postmodernism as slap-happy comedy, collage, parody, and so on, which provide lots of meaningful art forms, serve as the internal factors of" McDull" series ' success.

In this article, the writer analyses McDull series and gets enlightenment from them , hoping that can be better used for improving Chinese animation films.

\section{Retrospect to the history of Chinese animation.}

"Uproar in an Art Studio" made by the Wans brothers turned the new page in Chinese animation history in 1924.

Later, the first sound cartoon, The Camel's Dance was born in 1935. Then the first full-length animation in China, The Princess of Iron Fan became the fourth full-length animation in the world, following American animations, Snow White, Lilliput, and The Adventures of Pinocchio, which symbolizes that Chinese animation level was closer to the world-leading level.

From the founding of new China to the eve of Culture Liberation, Chinese animation developed into a rising period from the exploration stage. During this period, the most outstanding representative of Chinese animation is "Making Havoc in Heaven" made from 1961 to 1964, whose characters, actions, screens, sound effects etc, reached a new high in the world at that time. Above all, Chinese traditional art forks were blended into animation artistic techniques, which enriched the art forms of animation. Such animations as the first puppet cartoon, The Emperor's Dream, the first paper cutting cartoon - Zhu Bajie Eats Watermelon, the first water ink animated cartoon -Baby Tadpoles Look for Their Mother, as well as the first origami cartoon -A Cabbage, were all born in this period. 
Since then, Chinese animation seemed to usher in a flourishing age. However, when it came into Culture Liberation, during the period, none of cartoons was produced from 1966 to 1976. Later from 1972 to 1977, the number of cartoons produced per year is just around 2 or 4 . The continues 10 years' attack to Chinese animation following its new birth greatly affects its development.

During the period from 1978 to 1998, Chinese animation production seemed to get a little recovery, but the creative spirits of the early cartoon makers were lost. With the advent of Chinese reform and opening up, a great deal of excellent foreign animation works flooded into China, which frightened Chinese cartoon makers.

On the one hand, during this period the dilemma Chinese animation was faced with is the gap between Chinese animation and international level animations, which was really recognized by Chinese. While the brain drain resulting from Culture Liberation , as well as the poor techniques can't be compensated within a short period.

On the other hand, as China demand for animation increases gradually, their aethetics tend to diversity.

However, there were still many excellent animated works coming into existence during this period, such as Calabash Brothers, The Black Cat Sergeant, Story of Effendi, Shuk the Cat and Bet the Pet Mouse and so on. But all of them are more suitable for the infants and young children to enjoy.

In the 1990s, Chinese animation entered into a gradual transforming period, and developed towards industrialization mode. In 2000, Chinese animation world greeted the inspiring event---"Developing animation industry" in China is firstly proposed formally as a national policy. Chinese animation was ushered in a new exploration period, during which there were lots of failure, while there were still lots of animated works with creative spirits coming into being. When Chinese animation came into the fifth developing stage, in the first few years, the influence of McDull's birth to Chinese animation is indelible.

\section{Overview of McDull}

McDull is a cute cartoon character who comes from Hong Kong. The story is written by Xie Liwen , drawn by Mai Jidai . McDull the pig's life story is very common. However, it's the common life of such a cute character that makes the audience see themselves, their children as well as their neighborhood in it.

From the very beginning of its birth, McDull began to make a surprising effect and pleasant achievement by its cartoons, films, as well as its affiliate products.

Within more than 10 days when it was first put on, the box office earning of McDull breaks 10 millions. The following 2 works also earn enough money, at the same time bringing laughing to Hong Kong audience. Several films were shoot and put on. Since then Hong Kong has its own cartoon image. The birth of McDull makes Chinese cartoon character well-known in the world.

McDull series films include: My Life as McDull (2001) , McDull Princess De La Bun(2004), Ukulele (2006), McDull Kung Fu Kindergarten (2009), McDull Pork of Music ( July 10th, 2012), McDull My Mother and I (October 1st, 2014)

It has been more than 20 years since McDull was first serialized in the newspaper or published as McDull printing. Developing from the series film from 2001 to the present McDull, McDull stories as well as McDull brand have deeply rooted into every citizen and every children ' heart. At the same time win more support among audience in the mainland.

McDull is not just known as a cartoon character or a story, further more, in a way it has become an important part of Hong Kong popular culture. McDull, together with Hong Kong films, Hong 
Kong music , stars, Hong Kong Disneyland, Shopping Heaven, as well as Central on Hong Kong island, Kowloon Peninsula, Victoria Harbor, Causeway Bay, makes up Hong Kong culture identification. So it makes deep influences on every film audience's perception and judgment on Hong Kong.

It can't be denied that the creation, making, publishing and marketing of McDull story and McDull series films, together with its more than 20 years ' developing history are all successful. McDull not only provides us with a lively, moving and sentimental story, as well as a vivid, unique cartoon character, but also makes us see a process that a good business cultural brand grows step by step to be a big flourishing tree from a little seed under the fully ripe modern business society of Hong Kong.

\section{McDull's enlightenment to Chinese animation films}

First, the birth of McDull extends the expressing content of Chinese-made cartoons, adding new theme.

In retrospect to Chinese-made cartoon above in the article, we find a problem that Chinese-made cartoons have a obvious inclination, putting one-side focus on children audience as the group of cartoon receivers.

If the inclination is reasonable in the beginning of animation development, with the perception" Cartoons are only for children to see", it really limits its development in the latter stage.

The expressing content of cartoon should cover and contain everything. It has the super experience and super fantasy unmatched by the real person television or film.

In the cartoon world, all kinds of odd figures can become the main characters. The cartoon world can be both magical, fairy world and the real life. Cartoon can be so cute that makes children unwilling to let it out of their hands, and also can touch the adults' hearts by the philosophy implied in it.

In Japan, the cartoon consumers groups are diverse. From infants to the middle aged audience, they all can be cartoon fans, which is related to Japanese cartoon classification system.

Japanese realize that the development of animation needs diversity in its content, which means various groups should be included in cartoon consumer groups. In this condition, classification of cartoons, even the divided cartoon consumer groups were born with it.

There are Girls cartoon only for young girls, Warm-blooded Youngsters cartoon, Parent-Child cartoon, and cartoons only for adults telling stories about their professional career, as well as cartoons suitable for both young and old in the family. In general, Japanese cartoons are rich in content, and the cartoon consumer groups are multilayered.

With the growth of a group of new cartoon makers, Chinese are working hard to make the breakthrough in the situation that Chinese cartoons are only for children to enjoy. For example, in the plot of Lotus Lantern (1999), some romance element first appear, which is rare in Chinese animation before. And in Mad For Music (2000), the uproarious youth of the middle school students is put forward first as the expressing theme. However, even through a lot promotion work, these two works still can't get satisfactory word of mouth in the end.

At this time, McDull came into being in 2001.

Although the former 2 cartoon works have worked hard to enlarge the animation themes, My Life as McDull is the only cartoon work taken adults fully as its theme, as the same time it also makes success in forms of expression, sound, pictures and its language.

My Life as McDull elaborates the state in which human beings are living. McDull's growing process makes many adults recall their growth. That memory happens in the cartoon world which is 
provided by the film so much like the real world. So the pressure, helpless, disappointment and hope are bonded together in the bottom of the adults' hearts.

Since My Life as McDull put on, the biggest responses are from white-collar workers .For the first time adults are included in the cartoon audience group. Because of changes in theme, McDull gets rid of the teaching tone and the rigid ending where some principles must be explained to retrospect the cartoon' idea. In need of expressing the theme, blending adults' real feelings into the life details, making the audience taste that by themselves, get great progress in aesthetic feeling. In addition, using a animal to express human life, the wise design not only expands the imagination of cartoon, but also enriches the content implied by the cartoon. It's both a creation and a successful example for expressing cartoon implications.

In view of this, cartoon works can be fully consumed by adults, no need to be limited for infants and children. On the contrary, the expansion of cartoon theme will make great efforts on animation art development.

Secondly, the skilled utilization of sound, pictures, and language makes an example for Chinese animation. Those Chinese animation in the transforming stage are a little rigid in using sound, pictures, and language.

Take Lotus Lantern as example, in the latter part of the film, the singing and dancing scene of GA sister 's tribe which should be rousing and lively, is expressed a little rigidly without multiple angles and multiple field of view.

In addition to that, switching of scenes and language, the management of rhythm are not correct, which makes the whole plot seem to be inserted rigidly, making a feeling of tediously long.

In another example, in the duel between Chen Xiang and god Erlang, the scene is short of changes, which should be the climax of the whole film. First, two characters cast their weapons to each other, then god Erlang sends up a ray of light from his finger, and Chen Xiang is encircled by the light.

First, a close-up shot is given to the flying weapons, then the following close-up shot is given to two characters' facial expressions, each with a single screen. Furthermore, the composition elements in this plot are simple. The background of two characters are fully blank.

The rough pictures,together with the poor design of cartoon is another significant problem to be solved by the new generation of cartoon makers.

As we said above, in the scene of" the Song of Li Gen", the beautiful sound and pictures drunk the audience.

McDull's pictures are full of local flavor, giving modern animation another significant enlightenment that the animation should also be flexible.

Flexibility needs inheritance and change. Change here means to make changes and creations after learning and inheritance.

The aim of learning is to make better creations, and make local cartoons with our own identification, but not just simple imitation.

Chinese always regard the perspective of change as a important question. Early in the Northern and Southern Dynasties, Liu Xie's The Literary Mind and the Carving of Dragons has an article" Change". This thought can even be traded back on The Book of Change.

While in recent years, Chinese cartoon copying is making disasters. Code Warriors copies Japanese Digimon Adventure; Big-ear Tutu and Big Mouth Dudu have similar plot with Crayon Dhin-chuan; Lighting Line uses the routine of Bakusou Kyoudai Lets Go. Those Chinese-made cartoons have nothing new, unmatched with the models. 
After Chinese-made animation comes into industrialization, the production increase per year is doubled. Till 2010, Chinese animation production reached 0.22 million minutes. The number of Chinese-made films also reached 16, as the same time brushing box office constantly.

Before 2004, Chinese animation production is less than 4000 minutes per year. Only through 10 years, China jumped as the first animation producing country.

Problems and Countermeasures of the development of creative industries forum was hosted by Subcommittee of Education, Science, Culture, Health on December 2nd, 2012

In the meeting, Vice Chairman of CPPCC, Executive Vice Chairman of the Central Committee, Li Wuwei said,

" China is a big cultural country, but not a strong nation of culture."

In 2008, Hang Zhou, a French guest declared in the international animation festival forum," The animation production in France per year is only 10 thousand, but France is a real strong nation of animation. While Chinese original animation can reach 100 thousand, it's only a big nation of animation."

Facing with the awkward situation, it's high time that we should think about the basic problem of Chinese animation. Besides the narrow theme, the immature cartoon making and pictures with sound, Chinese cartoon makers also need to think about how to develop an animation with Chinese national characteristics, as well as how to develop an animation with local flavor, expressing typical feelings of the whole human beings, making Chinese-made animation acceptable in a larger realm.

Responding to that thought, My Life as McDull comes into being.

The story is set in Hong Kong. In the beginning of the cartoon, a large series of street scenes are viewed from the sky, later, the location shootings of Mong Kok, Big Block, The Peak, Cheung Chau, Outlying Islands Pier, Star Ferry Pier etc. appears.

Besides, there are plenty of old street scenes with the overpass, buses, billboards, various shops etc. The noodle shops and tea restaurants are daily destinations for Hong Kong people, they are also a part of the local culture, which isexpressed in the cartoon.

The headmaster of McDull's Spring Field Kindergarten speaks pure Teochew, which reflects the mixed dialects characteristic in Hong Kong. Cheung Po Tsai's treasure cave, the old legends in the old days, the Olympic gold medal won by Li Lishan, Hong Kong bidding for the Asian Games, reflects the present Hong Kong.

All of above makes the whole cartoon with a thick Hong Kong sense and cultural features. In addition, the use of Hong Kong-style comedy and sarcasm makes a strong flavor of Hong Kong style.

Since the founding of New China, before Culture Liberation, Chinese animation also had such creations as appearance of water ink cartoon and paper cutting cartoon. The coming out of McDull reminds cartoon makers of the old Chinese traditional spirits, and improves creation based on traditions.

At the same time, McDull with deep local flavor contains the moving emotions which can touch people in all districts and all races. This cartoon work, as "a meaningful form", expresses the universal living situation of modern people.

The pressure of living, as well as the experience of growth under this pressureis universal, and can draw resonance among people. Inserting universal emotionsof human into the film makes it not only belong to China, but also belong to all mankind.

\section{References:}


[1] Martin Heidegger. Being and time [m]. Chen Jiaying, Wang Qing, translation. Beijing: joint publishing, 2006.

[2] David, Arnold. Lin Bicui, Li Guifen translation. Brand Babysitting Handbook: 13 brand-name products promotion model reconstruction [m]. Taipei: China Times Publishing House, 1995.

[3] David Harvey. Yan Jia translation. Modern conditions one by one after discussion on the origin of cultural change [m]. Beijing: commercial press, 2003.

[4] Philip Kotler. Mei Ruhe, Mei Qinghao, Zhang Hang translation. Marketing management: analysis, planning and control [m]. Shanghai: Shanghai people's press, 1996.

[5] Matera Matei Calinescu. Gu Aibin, Li Ruihua translation. Five faces of modernity [m]. Beijing: commercial press, 2002.

[6] OG Jung. Translate Lu Xiaochen. And the spirit of art and literature. Beijing: Chinese workers press, 1988.

[7] Paul Paul Stobart. The Government educates, Wan Xinping, Song Zhen-translation. The power of the brand [g]. Beijing: China CITIC press, 2000.

[8] David peikedun, Amanda bulaodeli. Wang Xiaohui, Huo Chunhui translation. Integrated marketing communications [m]. Beijing: economic management publishing house, 2009.

[9] Geoffrey Randall. Zhang Xiangwen, Wu Yingna translation. Brand marketing [m]. Shanghai: Shanghai far-East press, 1998.

[10] Mike Featherstone. Liu, Jinming translation. Consumption culture and postmodernism [m]. Nanjing: Yilin Publishing House, 2000. 